\title{
Issues of Reader in Translation Studies: A case of Dawn of Dreams
}

\author{
Md. Rizwan Khan
}

\begin{abstract}
The reader response paradigms in the last century have rendered radical interpretations and theorizations to the literary pursuits. The culmination of the same was witnessed in the death of the author. The reader's issues have always also held a significant position in the deliberations of translated studies. But the translations studies have always been approached through the positions of translation as a process wherein lay the translator's connection and role exposed to analyses with an assumption of that the reader is position and involvement is fully understood and correctly estimated by the theorists. But this positioning of the reader does not emerge through verifiable sources which is not the case with readerresponse practices. The present paper takes up this insufficient positioning of the reader in the translation studies through the analysis of Dawn of Dreams which is Mehr Afshan Faruqi's translation of Abdus Samad's Urdu novel Khwabon Ka Savera. The paper surveys the theories and paradigms of translation studies and reader-response in order to foreground the need for a strengthened and proactive interface between the two. For the paper a survey was conducted among the readers and responses were solicited through a questionnaire. The findings, suggestions and conclusion supplicate the research questions wherein lay the need to signify the reader's role in translation studies.
\end{abstract}

Post 1970s has witnessed a surge in the reader-oriented paradigms in language and literary studies. This includes perspectives of translation studies too. Although the readers in the business of translation, notwithstanding the important stake 
that they have, have not had any radical and vocal representations in the theoretical quantum. This quantum eventually appears to be working on the nuances, methods and impacts of translation based in the understanding where the theorists, critics and translators work with an assumption that they all understand and know the reader. Even a simplistic assertion of the process of translation signifies the place of reader. The success and failure of a translated literary text depends primarily on readers. Once a text is translated, it goes to the readers of the target language (TL). In this process a translator acts as a medium to shift a text in the Source language (SL) to another text in the TL. Source Text (ST) now differs significantly from the Target Text (TT) in order to suit the readers / users of the TL. The readers now, become the evaluators of the text whether analyzing it consciously (like in the case of reviewers, critics, etc., a small number, but major voices) or unconsciously (common readers looking for leisure reading). In other words the success and failure of the translator and his/her manner and mode becomes directly proportionate to the level of perception of the translated text by the readers. The better is the perception and understanding of the text by the reader, the superior is the quality of translation. Reader thus occupies central position in the process of translation. Besides, it is assumed that a translation is purported to extend its readership with an intention of transferring the message/thought, the point of views, and the culture and tradition of the ST thus signifying the reader's position.

\section{Research Questions}

The present paper will reflect upon the following dynamics of translation as part of the research questions case study of Dawn of Dreams:

- What place for readers do the theories and practice in translation studies reflect?

- Whether the present translated text Dawn of Dreams successfully attracts a wider readership? 
- Whether the new readers (who cannot read the source language, Urdu, and can reach the text only in the target language, English, in the present case) are able to read, comprehend and enjoy Dawn of Dreams as a literary text?

- If no, then why? Is it because of a massive presence and availability of the lexis, situations, and culture of the source text into the English text, Dawn of Dreams?

- Is it that the presence (due to the postcolonial and post modern canonical notions) of local issues (partition/ zamindari), diction (terms that are used to address kinship in a Muslim family) and culture of a country (Indo-Pak) prove to be a barrier in the general comprehension of the new readership at global level?

- Whether Dawn of Dreams fulfills these expectations or simply remains a text for the limited purposes like specialized studies on translation, culture etc.

\section{Aim of the Present Study}

- The present paper is aimed at considering the text as an end product;

- The paper intends to list and study the extent of joy, comprehension and perception by the readers -both familiar and unfamiliar to the linguistic, cultural and sociopolitical aspects of the text.

- The paper is not aimed to be judgmental about the text/ translator; or about the levels of problems; or even the strengths and weaknesses of Dawn of Dreams as a translated literary text

\section{Methodology}

For the present purpose the researcher designed a questionnaire and sent it to the subjects (readers) along with a-soft copy of Dawn of Dreams. The readers were sent the soft 
copies with a request to read it (not like a reviewer or critic) and fill in the questionnaire with their observations. A total number of ten respondents from different countries were contacted, but only seven responded. One each from India, Pakistan and Saudi Arabia failed to give their responses until now.

Subjects. These readers belonged to India (two), Pakistan (Two), Arabs (four) (Saudi Arabia -2, Iraq -1, and Egypt-1), European (two) (one from Russia and one from Italy). These subjects are English teachers in their respective countries. Due to paucity of time, the researcher could not contact any native speaker of English. However, readership at international level is emphasized here because the present text has been translated from Urdu (a language of the Indo-Pak subcontinent) into English (a global language). The English readership both in India and abroad were taken into consideration.

The tenets of translation involve a text, a translator, source language, target language and readers. The permutations and combinations that emerge from these four tenets focus on varied perspectives that involve language, culture, psychology, sociology, linguistics and other disciplines. In literary translation the translator plays the role of the creative artist (writer, author, poet etc.) and there have been attempt in galore in order to critique/analyze/understand/clarify the role of the translator, and not the reader. It is often said, " ... Translator is the central figure in any translation activity as it is s/he who interprets and selects the method of translation taking into account various textual and contextual factor ... that vary from context to context, translator to translator and language to language". (Lakshmi 2007)

I focus on the other half of the translator/reader duality which seems to have been less or not much talked about. Following brief discussion about the types, methods, approaches, and theories postulated so far for various aspects of translation foreground the fact that majority of theorizations involve a passive positioning of the reader wherein the active stakes of the translator, text and language are analysed. The reader remains

\section{Translation Today}


an assumed entity since not too many studies are based on the responses of the actual readers. Somehow the reader-response paradigms have not inspired the reviews of the translated works as have been the case with literature in general.

\section{Approaches to Translation}

1. Translation studies so far have witnessed the shifts in approach to translation from 'linguistic' to 'textual', and to 'cultural; (which is still going on).

Linguistic approach of translation prevailed in the 1960s. According to this approach, Translation may be defined as "the replacement of textual material in one language (SL) by equivalent textual material in another language (TL)". (Catford 1965, 20)

The text was then seen as linear sequence of units, and translation was merely a transcoding process involving the substitution of a sequence of equivalent units. This is clearly expressed in Werner Koller's definition of 1972. (Koller 1972, 6970, also see Goodenough 1964)

According to the textual approach that prevailed in 1970s the text is viewed not simply as a sequence of sentences as each sentence in itself is a string of grammatical items. Thus textual analysis proceeds from the macro to micro level-from 'top down' -, its aim being to trace a web of relationships, the importance of individual items being decided by their function in the text. Nor should the text itself be studied in isolation, but rather as a part of a given situation against a particular sociocultural background (Kussmaul 1986; Honig and Kussmaul 1982; Robert de Beaugrande 1978).

This postulates the basis of the cultural approach (that popularized in the 1980s onwards) whereby language is viewed, not merely as a code, as in linguistic approach, but as an integral part of the living world, and translation is not simply a matter of equivalent items or even an equivalent text, but is essentially "TToriented" (Toury 1981 (1980:35-50); see also Honig and Kussmaul 
1982), and concerns the interplay of language, text, situation and culture. This approach gives a space to the readers in the name of culture and situation.

In cultural approach thus translation is no longer seen as code switching, but as a form of action, which is integrated into a complex of related actions and which is dependent on the specific function prescribed by those related actions. (Vermeer 1986; Holz-Manttari 1984 and 1986; Reiss and Vermeer 1984 also Kussmaul 1982)

2. In the history of translation studies various formulations have been laid down from time to time but almost all of them are premised within the perspective of the translator or the text.

- Bible translation

- $\quad$ Education and the vernacular ( $8^{\text {th }}$ century- $15^{\text {th }}$ century)

- Early theorists like Dolet, George Chapman (Epistle to the Reader of his translation of The lliad)

- The Renaissance like Edmond Cary (translator acts as a revolutionary activist and translation being the primary activity rather than the secondary activity)

- Seventeenth century like Sir John Denham, Descartes, Abraham Cowley and John Dryden (stress on close reading of the original by the translator to note the details of style and manner)

- $\quad$ Eighteenth Century like Dr. Johnson, Alexander Fraser Tytler (concerned with the problem of recreating an essential spirit, soul or nature of the work of art)

- Romanticism like Shelley, Coleridge, Schlegel-Tieck (translation of poetry and problems concerned)

- Post Romanticism like William Morris

- The Victorians like Longfellow, Fitzgerald (translator as a 
skillful merchant offering wares to the discerning few).

3. The types of translation pose a picture where it is difficult to entail reader as thinking and responsive figure:

- Text based approaches and methodologies

- Word-for-word translation

- Literal

- Faithful

- Semantic (close to semantic and semantic of the original)

- Free (where addition, deletion, and modifications are possible)

- Communicative (Newmark 1981, Communicative and Semantic translation, produces on its readers an effect as close as possible, smooth and fluent)

- Adaptation

4. Only such Methods as Domesticating (Author to Reader) and Foreignizing (Reader to the Author) (Schleiermacher 1813 in Lakshmi 17 and 116; Venuti 1995) take the readers into consideration.

5. To evaluate translated literary text twelve parameters are suggested by $\mathrm{H}$. Lakshmi 2007). Here items i, vii and viii focus on the readers.

i Closeness to the original

ii Readability and fluency

iii Effectiveness of the translation

iv Authority of the original

v Credibility of the translation 
Issues of Reader in Translation Studies: A case of Dawn of Dreams

vi Purpose of the translation

vii Intended readership of the translation

viii Acceptability of the text in the Target Language

ix Place and status of original in the source language

x Current literary trends

xi Relationship between SL and TL

xii Likely place and status of the translated text in target literature

\section{Translation Typology: Some Representation of the Readers}

- Translation as a scholar's activity, where the pre-eminence of the SL text is assumed de facto over any TL version.

- Translation as a means of encouraging the intelligent reader to return to the SL original.

- Translation as a means of helping the TL reader become the equal of what Schleiermacher called the better reader of the original, through a deliberately contrived foreignness in the TL text.

- Translation as a means whereby the individual translator who sees himself like Aladdin in the enchanted vaults (Rossetti's imaginative image) offers his own pragmatic choice to the TL reader.

- Translation as a means through which the translator seeks to upgrade the status of the SL text because it is perceived as being on a lower cultural level.

\section{Reader -Related Issues in Translation Studies}

Studying the average reader, Lotman (1970) determines four essential positions of the reader: 
- Where the reader focuses on the content as matter i.e. picks out the prose argument or poetic paraphrase.

- Where the reader grasps the complexity of the structure of a work and the way in which the various levels interact.

- Where the reader deliberately extrapolates one level of the work for a specific purpose.

- Where the reader discovers elements not basic to the genesis of the text and uses the text for his own purposes.

\section{Major Reader Response Paradigms}

At the base of the centralizing of the reader in literature studies lay the researches that were initiated in the early half of the last century when the formalistic approaches to language and literature studies emerged. The New Critics worked "to secure the text objectively with verifiable results in the critical process" (Lang, Web) and the Reader-Response critics paved the way for the reader to focus on processes of mental orientation in the act of reading. Wolfgang Iser says

The phenomenological theory of art lays full stress on the idea that, in considering a literary work, one must take into account not only the actual text but also, and in equal measure, the actions involved in responding to that text... The convergence of text and reader brings the literary work into existence. (1972)

Stanley Fish (1970) asserts on a radical approach to reader-response criticism in the tradition of neo-pragmatism and conventionalism. "His assertion is that the reader manufactures the sense or meaning of the text. Meaning no longer inheres in the text, but is fully located within the reading community. Thus the reader's presuppositions are not something to be overcome, they are inescapable. The "interpretive community" is a reading public that shares a strategy or approach to interpretation. The text is not an object that can be approached and examined from 
the outside." (Lang, Web)

Roland Barthes (1974) sees the place of the literary work as that of making the reader not so much a consumer as a produce of the text. Julia Kristeva (1970) sees the reader as realizing the expansion of the work's process of semiosis. The reader then translates or decodes the text according to a different set of systems and the idea of the one 'correct' reading is dissolved. At the same time, Kristeva's notion of intertextuality that sees all texts linked to all the other texts because no text can ever be completely free of those texts that precede and surround it, is also profoundly significant.

The above survey shows that the reader's position is not at par with reader response theorizations in literature studies. The reader is taken for granted in translation studies. All the guidelines / norms / suggestions / clarifications / analyses are centered on the translator. Despite the fact that in modern literary studies readeroriented approaches are considered more relevant the translation studies have not been guided by these phenomena.

Reader-oriented or reader-centered approach in translation studies should not just remain confined to a translator's note to the readers. One of the basic beliefs of literary translation is that it is done to make a text available for those readers who are not able to read the text in SL and it is not done for the translator (this may not be true in the case of creating a literary piece because the aesthetic pleasure and reason to write may not always be guided by the readers' choice for the writer/novelist/poet etc. But a translator only translates for the reader and never for himself/ herself.) Thus by not taking into consideration this guiding tenet of literary translation the theorizing in translation studies remains an erroneous phenomena. For this reason I have chosen to take up the following discussion of Dawn of Dreams from the point of view of the readers.

Data Analysis. An analysis of the data gathered through the questionnaire (Appendix) suggests the following about Dawn of 


\section{Dreams:}

1. Item 1: All find it to be an "interesting" text due to i) lucid and coherent use of simple language; and ii) (European view) exploring a totally new issue.

2. Except the readers of the Indian subcontinent, all say that "the language used in the text is distinct from their own variety of language"

3. Readers of the non Indian subcontinent found the text sufficiently loaded with features of Indian variety of English.

4. These readers said that such features created problems "To Some Extent" in the general enjoyment and comprehension of the text.

5. Majority (the Arabs) found it to be a "Difficult" text, but the Europeans call it "tolerable" as it is study of a distant exotica for them.

6. Words and expressions that generally created problems are listed as follows: Apa, Dulhabhai (name), (Ragho) Bhaiyya, Miyan, Haveli (Europeans only), Bade sarkar, Patwariji, Gumashtaji, Zamindari, etc, etc.

7. All except Indo-Pak readers found the text to be problematic due to social, cultural, and political background of the text; some cultural aspects exclusively related to AMU were problematic even for the Pakistani readers to a certain extent.

8. The Europeans found themselves "totally alien", while most Arabs found themselves "distantly familiar"; one Saudi says he is "familiar to some extent".

9. While One Saudi and the Iraqi reader found the text to be challenging due to "handling the language used" in the text; the others (European, Egyptian, and a Saudi), except IndoPak readers, found $\bullet$ it difficult to comprehend mainly due to not "understanding the context" (social, political, and cultural 
aspects).

10. While Indo-Pakistani and the Europeans found it "comfortable" in dealing with the context, the rest found it "Difficult". They found difficulty in handling with such socio-cultural aspects as "abolition of Zamindari" and its impact, "Partition", "Aital kursi", "AMU" episodes, etc.

11. Almost all refused to accept that "such a literary text with typically localized Indian context can be sufficiently enjoyed and comprehended by a culturally distant reader too". As a reason for this, the majority calls it so due to "the backdrop / context of the story", while the Russian calls it so due to "the language in general".

12. Dawn of Dreams is identified by all the readers as translated text on the basis of the language, expressions, culture etc.

\section{Findings / Inferences / Conclusion / Suggestions}

Findings/Inferences. Being translated in English, the Dawn of Dreams promises to attract the English knowing readers in general. The subjects who belong to the context of English as Foreign Language (where English is neither used as the mother tongue, nor for interpersonal purposes in their everyday life, like the ones from Egypt, Italy, Russia, and Saudi Arabia) face problem in tackling the use of the Indian variety of words, expressions and jargons and the Indian social, cultural and political instances. Such linguistic and cultural features became reasons for obscurity and barriers in communication for such readers. It is important to mention here that the readers from India and Pakistan do not find such features as obstacles either in enjoyment while reading or in comprehending the text, while the others do face a problem. This suggests that mere change of language -from SL to TL -is not enough for proper comprehension of the text. Certainly there is something more beyond the linguistic aspect of a language that needs to be perceived by the readers. For this a translator may provide with footnotes, references etc more, even though such 
efforts apparently take away the challenge from the readers, but a translated text is definitely not free from its own challenges to offer to the readers and sometimes it is advisable to minimize the intended challenges in reading in order to increase the readability of the text. A literary translation, thus, is a device of art used to release the text from its "dependence on prior cultural knowledge" (Herzfeld 2003 in Albakry). However, it is not an easy task to transplant a text rooted in one culture into another and this is the reason that a translator cannot stop the loss in translation but at the same time a translator needs to keep in mind that which loss is less damaging from the point of view of the readers. Thus a translator has to pick between providing for a better comprehension of the text as cultural carrier or letting it remain a text true/close to its SL and making compromises at the cost of readers' share of comprehension of the text.

These aspects make a point in case for some measures that needs to be taken in order to minimize such obstacles / barriers faced by readers who are unfamiliar to the localized linguistic and cultural aspects. Scholars and translators need to work on the agenda of reaching out to the maximum readers otherwise such translated texts will remain confined to the Indian subcontinent. Such translated text will not be suitable for the English knowing users of the world. In order to meet this lacunae, Popovic (1970) has advocated the freedom for the translator 'to differ organically, to be independent', provided that independence is pursued for the sake of the original in order to reproduce it as a living work for the readers. Meenakshi Mukherjee in H. Lakshmi (2007) voices the same when she talks of the following two problems:

- Difficulty of expressing the cultural and sub-cultural nuances of Indian life.

- Problem of addressing a heterogeneous group of readers with varied backgrounds and experiences.

Keeping in mind Popovic's concept of 'independence' and Mukherjee's 'problems' as cited above, in Dawn of Dreams the 
following aspects could have been more reader friendly in order to extend the readership in India and abroad.

- Chapter 3 reflects upon the inadequateness and abruptness in the novel. This is certainly on the part of the novelist, but may be mended for the extended readership.

- The context of AMU chapters 13-20 shows assumption, as if all readers are aware of the AMU lifestyle.

- Linguistic features like Gumashtaji, Patwariji, mohajirs, miyan chapter 3, 32; cultural aspects like sine die at AMU chapters 16-17, Thursday/Friday being the alms day at mosque; Muslim-Hindu tension and its subsequent impact as the biased behavior in Afaq's admission to college chapter 12 , getting a room in the government guest house chapter 37etc. are too rooted in the milieu.

Conclusion and Suggestions. In this way such texts will successfully be the carriers of native culture and will not merely end up becoming the case studies in culture and translation studies. I have attempted to create space for the readers' position in translation studies by looking at various dynamics of Dawn of Dreams as a translated text, through readers' point of view. The theoretical aspect remains to be documented as this paper simply analyses the responses of the readers and draws the inferences. I have not surveyed my sample among various Indian readers for the reason that entirely different paper and entirely different foci are needed to deal with the dynamics of the text because the readers in India have different issues with the familiarity, culture, language, syntax etc. of Dawn of Dreams. The translation studies going on in Israel, Russia, Germany etc are examples to inspire the Indian context to standardize the issues of translation studies in India. India being the country of multilingualism and multiculturalism has a lot to offer to the global quantum of literary translation studies because the problems / challenges / clarifications / findings / analyses of the Indian context are going to be based on the uniqueness of the Indianness. 


\section{REFERENCE}

Al Bakry. "Linguistic and Cultural Issues in Literary Translation". Web. Accessed on June 11th 2015.

Barthes, Roland. S/Z. London: Cape. 1974. Print

Bassnett, Susan. Translation Studies. London and New York: Routledge. 2002. Print

Catford, J.C. A Linguistic Theory of Translation: An Essay in applied Linguistics. London: Oxford University Press. 1965. Print

De Beaugrande, Robert. 1978. Factors in a Theory of Poetic Translating. Assen: Van Gorcum Goodenough, Ward H.1964. Cultural Anthropology and Linguistics. In Dell Hymes (ed.) Language in Culture and Society: A Reader in Linguistics and Anthropology. New York: Harper and Row. 1978. Print

Fish, Stanley. "Literature in the Reader: Affective Stylistics". New Literary History.Vol. 2, No. 1, A Symposium on Literary History (Autumn, 1970), The Johns Hopkins University Press. 123-162 (Web)

Honig, Hans G. and Kussmaul. Strategie der Ubersetzung: Ein Lehrund Arbeitsbuch. Tubingen:Narr. 1982. Print.

Holz-Manttari, Justa. Translatorisches Handeln: Theorie und Methode. Helsinki: Suomalainen Tiedeakatemi. 1984. Print

--------. Translatorisches Handeln -theoretisch fundierte Berufsprofile. In: M. Snell $\neg$ Hornby (ed). Ubersetzungswiss nschajteine Neuorientierung. Tubingen; Francke. 348-374. 1986. Print.

Iser, Wolfgang. 'The Reading Process: A Phenomenological Approach'. New Literary History. Vol. 3, No. 2, On Interpretation: I (Winter, 1972). The Johns Hopkins University Press. 279-299. Web

Koller, Werner. Grundprobleme der Ubersetzungstheorie: Unter besonderer Berucksichtigung schwedisch-deutscher Ubersetzungsjalle. Bern:Francke. 1972. Print

Kristeva, Julia. Le texte du roman. The Hague and Paris: Mouton. 
Issues of Reader in Translation Studies: A case of Dawn of Dreams

1970. Print

Kussmaul, Paul. Ubersetzen als Entschedungsfalle: die rolle der fehleranalyse in der Ubersetzungsdidaktik. In: M.Snell-Hornby (ed) Ubersetzungswissenschajt eine Neuorientierung. Tubingen;Francke. 206-229. 1986. Print

Lakshmi, H. Translation Studies: Theory and Practice. Booklinks Corporation: Hyderabad. 2007. Print

Lang, Chris. 'Brief History of Literary Theory'. Web. Accessed on June 6th 2015.

Lotman, Juri. Struktura Khudozhestvennogo Teksta (Moscow: Iskusstvo, 1970) Tr. La struttura del testo poetico Milan: Musia. 1972. Print

M. Snell-Hornby (ed). Ubersetzungswissenschajt eine Neuorientierung. Tubingen;Francke. 206-229. McGuire, Susan Bassnett. 1980. Translation Studies. London: Methuen. 1986. Print

Mukherjee, Meenakshi. The Twice Born Fiction. New Delhi: Heinmann. 1971. Print

Munday, Jeremy, (ed). The Routledge Companion to Translation Studies. London and New York: Routledge. 2009. Print

Neumark, Peter. Approaches to Translation. London: Peragamon. 1981. Print

\section{Print} . A Textbook oj Translation. New York: Prentice-Hall. 1988.

Popovic, Anton. 'The Concept of "Shifts in Expression" in Translation Analysis' in James Holmes (ed.), The Nature oj Translation. The Hague and Paris: Mouton. 1970. Print

Reiss, Katharina anf Hans J.Vermeer. Grundlegung einer allgemeinen Translationatheorie. Tubingen: Niemeyer. 1984. Print

Toury, Gideon. (Ed.). Translation Across Cultures. Bahri Publications, New Delhi. 1988. Print

-------. Translated Literature System, norm, performance -Toward 
a TT oriented approach to literary translation. In Even-Zohar and G. Toury (eds.) Theory of Translation and Intercultural Relations (Poetics Today 2.4) Tel Aviv: The Porter Institute for Poetics and Semiotics, 9-27. 1981. Print.

Venuti, Lawrence. The Translator's Invisibility: A History of Translation. London and New York: Routledge. 1995. Print

Vermeer, Hans J. and Mary Snell-Hornby. Die Szene hinter dem Text: "Scenes-and ᄀframes semantics" in der Ubersetzung. In: M. SnellHornby (ed). Ubersetzungswissenschaft ᄀeine NeuorientierunSf Tubingen;Francke. 184-205. 1986. Print

\section{Appendix}

\section{Questionnaire}

This questionnaire is intended to collect your views regarding some aspects of the text 'Dawn Of Dreams' that you recently read. The researcher assures you that your feedback will be kept confidential and will be used purely for research purposes. Do not hesitate to add any (number of observation) observation that you made while reading the text, but have not been raised in this questionnaire.

1. How do you evaluate the text 'Dawn of Dreams'?

\section{Very Interesting/Interesting/Just acceptable/Dull}

Please give reason for your response by mentioning a holistic opinion on the basis of your reading:-

2. Did you find the language (for instance, diction, jargons, usage, syntax) used in the text distinct or distant from your own variety of English? 
Yes I No

3. Did you find the text heavily loaded with features (for instance, diction, jargons, usage, syntax) of Indian Variety of English?

Yes I No

If 'Yes' did such a presence of Indian variety of English create a problem in the general enjoyment and comprehension of the text?

Yes $\quad$ No

If 'Yes', to what extent did you find the text to be difficult?

Very difficult / Difficult / Tolerable / Intolerable

4. Please mention, in the space provided below, some instances from the text, justifying your response for the previous question:

5. Did you find some problems of comprehension due to the typical Indian (Social, political, and Cultural) background of the text?

Yes $\quad$ No

6. How familiar did you find yourself to the context (social, political, and cultural) of the text?

Very Familiar / Familiartosomeextent / Distantlyfamiliar/ Alien

7. From the point of view of comprehension, which one of the following was more challenging? (Please rate your response with ' 1 ' as the most challenging; and ' 4 ' as the least challenging).

\section{i. Handling the Language used}


ii. Understanding the Context (social, political, and cultural aspects)

iii. Getting at the message

iv. Comprehending the author's point of view / the issue dealt with in the text

8 How do you evaluate your level of difficulty while dealing with the context?

Very difficult / Difficult / Tolerable / Intolerable

9 Please mention, in the space provided below, some instances from the text justifying your response to previous question:

10 Do you think that such a literary text with typically localized Indian context can be sufficiently enjoyed and comprehended by a culturally distant reader too?

\section{Yes / No}

11 While reading this text did you ever feel that it is a translated text from some Indian language? Yes / No

If 'yes', what made you feel so:

i Some expressions in the text

ii The language in general

iii The backdrop / context of the story

Any other aspect, please specify: 